\title{
Abdominal and pelvic adhesions: Possible role of leiomyomas and skin scar anomaly in profiling high risk patients
}

\author{
Emmanuel Nzau-Ngoma ${ }^{1 *}$, Jean-Marie Mbuyi-Muamba ${ }^{2}$, Esimo Mboloko $^{1}$, Massamba Lebwaze ${ }^{3}$ \\ ${ }^{1}$ Department of OB-GYN, University Hospital of Kinshasa, Kinshasa, DR Congo \\ ${ }^{2}$ Department of Internal Medicine, University Hospital of Kinshasa, Kinshasa, DR Congo \\ ${ }^{3}$ Department of Clinical Biology, University Hospital of Kinshasa, Kinshasa, DR Congo \\ Email: emdango@gmail.com
}

Received 3 December 2013; revised 28 December 2013; accepted 4 January 2014

Copyright (c) 2014 Emmanuel Nzau-Ngoma et al. This is an open access article distributed under the Creative Commons Attribution License, which permits unrestricted use, distribution, and reproduction in any medium, provided the original work is properly cited. In accordance of the Creative Commons Attribution License all Copyrights (C) 2014 are reserved for SCIRP and the owner of the intellectual property Emmanuel Nzau-Ngoma et al. All Copyright (c) 2014 are guarded by law and by SCIRP as a guardian.

\section{ABSTRACT}

Background and aims: Adhesions can cause important morbidity including abdominal and pelvic pain, intestinal obstructions, and infertility. When adhesions are formed, there is no efficient method, nowadays, to resolve them, thus the reduction of their prevalence relies on the prevention. Profiling high risk patients for abdominal and pelvic adhesions (APA) is an important step to this prevention. The risk factors of adhesions in our institution, the association between APA, leiomyomas and skin scar anomaly (SSA) were investigated. Methods: A cross-sectional study was conducted from March 1st to June 30th 2013 including patients who underwent laparotomy or laparoscopy. Patients' characteristics, presence of a SSA and leiomyomas, as related to adhesions, were analyzed. Student's t, Pearson's Khi-square, Fisher's Exact, Mann-Whitney tests and logistic regression were used. $P$ values $<0.05$ were considered statistically significant. Results: The frequency of adhesions was $41.74 \%$. Patients had a mean age of $32.69 \pm 8.94$ years. Those with a previous abdominal surgery (PAS), SSA and leiomyomas had respectively 12 times [OR: 11.98, CI95 (4.63 - 30.97)], 3 times [OR: 2.79, CI95 (1.16 6.71) and 2.5 times [(OR: 2.49, CI95 (1.07 - 5.78)] more adhesions. In logistic regression, a PAS and leiomyomas remained associated significantly to adhesions with $p=0.000$ and $p=0.037$ respectively. Conclusion: In peritoneal adhesions, leiomyomas and SSA are other factors that may allow a cautious selection of high risk patients who must benefit from particu-

${ }^{*}$ Corresponding author. lar attention during surgery. Further well designed studies are necessary to investigate the accurate clinical relation among those three conditions.

\section{KEYWORDS}

Peritoneum; Peritoneal Adhesions; Abdominal Adhesions; Abdominal Surgery; Leiomyomas; Skin Scar; Kinshasa

\section{INTRODUCTION}

Abdominal and pelvic adhesions (APA) are abnormal connections between two abdominal or pelvic surfaces normally separated [1]. Their incidence is difficult to establish in general population given the lack of complaints in many cases [2,3], the existence of other risk factors apart from the evident surgical one $[2,4,5]$, and the need for invasive explorations to their diagnosis. Laparotomy and laparoscopy remain then the gold standard methods for the diagnosis [6]. Thus, data reported in literature are those from surgery or necropsy, and the overall incidence of postoperative adhesions varies from $63 \%$ to $97 \%$ [4,7].

Adhesions can cause important morbidity including abdominal and pelvic pain, intestinal obstructions, and infertility [8]. In fact, they are the leading cause of intestinal obstructions in developed world [9] and are responsible for $20 \%$ - $40 \%$ of infertility $[5,10]$. In addition to their morbidity, they may also result in prolonged operating time, inadvertent organs injuries and high financial cost $[8,11]$.

In their genesis, they can be classified as congenital or acquired $[7,12,13]$. The risk factors for acquired adhesions encompass an intrinsic individual predisposition [14-16] and a history of laparotomy, perforated appendix, intestinal 
inflammatory disease, endometriosis and pelvic inflammatory disease [17-20].

When adhesions are formed, there is no efficient method, nowadays, to resolve them [21]. The reduction of their prevalence should then rely on the prevention, stressing on the profile of high risk patients, on the principles of microsurgery $[4,12,22]$ and on the use of multiple preventive therapies which are expensive and not always available in many settings.

Differences are observed on the conditions of surgical practice and the environmental factors from one region of the world to another, and this could presage variability in some characteristics of adhesions. Sub Saharan African environmental situation, particularly related to surgical practice $[23,24]$ and other factors such as postoperative infections [24], sexually transmitted infections [25] etc., might predict high prevalence of adhesions. In addition, some conditions such as leiomyomas and keloids, whose prevalence has been found higher in black skinned people [26], share many characteristics with adhesions [27]. Since one of the implicated factors of these is the fibroblast activity, it can be speculated that the prevalence of adhesions traces the same pattern.

The aim of the study was to determine the risk factors of adhesions in our institution, and to determine the association between APA and two pathologies with fibrotic disorder: leiomyomas and skin scar anomaly (SSA).

\section{MATERIAL AND METHODS}

We conducted a cross-sectional study from March 1st to June 30th 2013 in the Department of Obstetrics and Gynecology of the University Hospital of Kinshasa, Democratic Republic of Congo. All patients who underwent laparotomy or laparoscopy for various indications were enrolled after consent. Patients whose surgery did not allow entire exploration of the pelvic and abdominal cavity were excluded. Socioeconomic characteristics, medical and surgical histories of patients were recorded. During surgical procedure the presence of adhesions and leiomyomas was noted. The adhesions description was done according to the Adhesion Scoring Group grading (ASG) [28].

Previous abdominal surgery (PAS) was defined as all surgical procedure in the past, with entry into the pelvic or abdominal cavity. Age of adhesions was defined as the time between the last abdominal surgery and the present surgery. According to their severity, based on the ASG grading, adhesions were divided into three groups: mild (1 - 46), moderate (47 - 92) and severe (93 - 138). The economic status was defined according to the Adjusted Poverty Index (API) based on the possession of some items by the household. A SSA was retained when patients had keloids or hypertrophic scar.

\subsection{Statistical Analysis}

The Statistical analysis was performed using SPSS 17.0. For parametric data, with normal distribution, comparison of means was done with Student's t test. The Pearson Khi-square and the Fisher's Exact tests were used for comparison of proportions. In bivariate analysis, the Odds Ratio with 95\% confidence intervals (CI) served to measure association between factors. Logistic regression analysis was used to generate the OR, after checking the association between predictors and dependent variable. The difference between groups, for non-parametric data, was analyzed by Mann-Whitney test. Values of p less than 0.05 were considered statistically significant.

\subsection{Ethical Considerations}

The protocol was approved by the Ethical Committee of the Kinshasa University School of Public Health. Informed consent was obtained before inclusion of patients.

\section{RESULTS}

During the study period, 119 patients underwent abdominal and/or pelvic surgery. Four patients were excluded from analyses due to failure of perioperative description of adhesions ( 2 cases of peritonitis and 2 of ovarian cancers). Forty-eight patients (41.74\%) were found to have abdominal and/or pelvic adhesions. In patients without PAS ( $\mathrm{n}=52$ ), $13.46 \%$ had adhesions versus $65.08 \%$ in patients with PAS. In this latter group, the frequency of postoperative adhesions varied from $54.76 \%$ in "a unique PAS” group $(\mathrm{n}=42)$ to $100 \%$ in “at least 3 PAS” group $(\mathrm{n}=6)$ (Table 1$)$.

The mean age (years \pm SD) of patients was $32.69 \pm$ 8.94 and the median parity (median; range) was 2; 1 - 3 . There was no difference between groups of patients with and without adhesions in terms of age ( $p=0.152)$, parity ( $p=0.214)$, level of education ( $p=0.565)$, economic level $(p=0.272)$ and the type of PAS; cesarean or not $(p=0.089)$ (Table 1$)$. Whereas, the difference was significant between the two groups considering the history of PAS ( $p=0.000)$ and the presence of SSA ( $p=$ 0.019). In patients who underwent a unique PAS, the CD represented $70.59 \%$ of surgeries performed. Considering the same group of patients but without CD, the appendectomy ranked first with $25 \%$ of cases.

Adhesions had a median age (median; range) of 3.72; 1.67 - 10.12 years. There were no severe adhesions. All others but two (95.8\%) were mild. The median score of ASG (median; range) was 13.00; 6.00 - 22.50. In patients with history of a unique PAS $(n=42)$, the adhesions score did not differ $(p=0.85)$ when this surgery was 
Table 1. Socioeconomic and medical history characteristics of patients.

\begin{tabular}{|c|c|c|c|c|}
\hline Variables & Adhesions & No-adhesions & Total & $\mathbf{p}$ \\
\hline Age (years) of patients (mean \pm SD) & $34.13 \pm 7.91$ & $31.69 \pm 9.53$ & $32.69 \pm 8.9$ & 0.152 \\
\hline \multicolumn{5}{|l|}{ Level of education, n (\%) } \\
\hline Illiterate & $0(0)$ & $2(100)$ & $2(100)$ & \multirow{4}{*}{0.565} \\
\hline Primary & $2(25)$ & $6(75)$ & $8(100)$ & \\
\hline Secondary & $22(42.30)$ & $30(57.70)$ & $52(100)$ & \\
\hline University & $24(45.28)$ & $29(54.72)$ & $53(100)$ & \\
\hline \multicolumn{5}{|l|}{ Economic level, n (\%) } \\
\hline High & 15 (57.69) & $11(42.31)$ & $26(100)$ & \multirow{4}{*}{0.272} \\
\hline Middle high & $26(36.11)$ & 46 (63.89) & $72(100)$ & \\
\hline Middle & $6(42.86)$ & $8(57.14)$ & $14(100)$ & \\
\hline Low & $1(33.33)$ & $2(66.67)$ & $3(100)$ & \\
\hline Parity (mean \pm SD) (median; range) & $2.54 \pm 1.92$ & $2.40 \pm 2.27$ & $2.46 \pm 2.13(2 ; 1-3)$ & $0.214^{*}$ \\
\hline \multicolumn{5}{|l|}{ PAS, n (\%) } \\
\hline Yes & $41(65.08)$ & $22(34.92)$ & $63(100)$ & \multirow{2}{*}{0.000} \\
\hline No & $7(13.46)$ & 45 (86.54) & $52(100)$ & \\
\hline \multicolumn{5}{|l|}{ Type of PAS $^{\dagger}, \mathbf{n}(\%)$} \\
\hline $\mathrm{CD}$ & 12 (70.59) & $5(29.41)$ & $17(100)$ & \multirow{2}{*}{0.089} \\
\hline Non-CD & $11(44.00)$ & $14(56.00)$ & $25(100)$ & \\
\hline Appendectomy & $4(25.00)$ & $12(75.00)$ & $16(100)$ & \\
\hline Myomectomy & $2(100)$ & $0(0)$ & $2(100)$ & \\
\hline Ovarian cystectomy & $2(100)$ & $0(0)$ & $2(100)$ & \\
\hline Ovarian cystectomy and appendectomy & $3(60.00)$ & $2(40.00)$ & $5(100)$ & \\
\hline \multicolumn{5}{|l|}{ Number of $\mathbf{P A S}^{\ddagger}, \mathbf{n}(\%)$} \\
\hline 1 & $23(54.76)$ & $19(45.24)$ & $42(100)$ & \multirow{4}{*}{0.084} \\
\hline 2 & $12(80.00)$ & $3(20.00)$ & $15(100)$ & \\
\hline 3 & $4(100)$ & $0(0.00)$ & $4(100)$ & \\
\hline 4 & $2(100)$ & $0(0.00)$ & $2(100)$ & \\
\hline \multicolumn{5}{|l|}{ SSA, n (\%) } \\
\hline Yes & $17(60.71)$ & 11 (39.29) & $28(100)$ & \multirow{2}{*}{0.019} \\
\hline No & $31(35.63)$ & $56(64.37)$ & $87(100)$ & \\
\hline
\end{tabular}

SD: Standard deviation, PAS: Previous abdominal surgery, CD: Cesarean delivery, SSA: Skin scar anomaly. ${ }^{*}$ : Mann-Whitney test, ${ }^{\dagger}$ : computed for patients a unique PAS $(n=42),{ }^{\ddagger}$ : computed for patients with PAS $(n=63)$.

cesarean delivery (CD) as compared to other procedures (data not shown). The uterus was the most concerned organ by adhesions (28.83\%) followed by the bladder and the abdominal wall with respectively $23.31 \%$ and $21.47 \%$ (Table 2).

Associated factors to adhesions are gathered into Ta- ble 3. Adhesions were found 12 times more frequently in PAS group as compared to patients without history of PAS [OR: 11.98, CI95 (4.63 - 30.97)]. Furthermore, patients with at least 2 PAS were 5 times more likely to be found with adhesions than those with one PAS [OR: 4.96, CI95 (1.27 - 19.40)]. 
Table 2. Characteristics of adhesions.

\begin{tabular}{|c|c|c|c|}
\hline Variables & $\mathbf{n}$ & $\%$ & Median, range \\
\hline Age (years) ${ }^{*}$ & 41 & N/A & $3.72 ; 1.67-10.12$ \\
\hline \multicolumn{4}{|l|}{ ASG score } \\
\hline $1-46$ & 39 & 95.12 & \multirow{2}{*}{$13 ; 6.00-23.50$} \\
\hline$\geq 47$ & 2 & 4.88 & \\
\hline \multicolumn{4}{|c|}{ Organs affected $(n=163)^{\dagger}$} \\
\hline Uterus & 47 & 28.83 & $\mathrm{~N} / \mathrm{A}$ \\
\hline Bladder & 38 & 23.31 & $\mathrm{~N} / \mathrm{A}$ \\
\hline Abdominal wall & 35 & 21.47 & N/A \\
\hline Greater omentum & 17 & 10.43 & $\mathrm{~N} / \mathrm{A}$ \\
\hline Adnexa & 16 & 9.82 & $\mathrm{~N} / \mathrm{A}$ \\
\hline Bowels & 10 & 6.14 & N/A \\
\hline
\end{tabular}

N/A: not applicable, ASG: Adhesion Scoring Group, ": computed only for postoperative adhesions $(n=41),{ }^{+}$: almost all patients had more than one organ affected.

Table 3. Bivariate analysis of factors associated to adhesions.

\begin{tabular}{ccc}
\hline Variables & OR & CI $_{95}$ \\
\hline PAS & 11.98 & $4.63-30.97$ \\
Yes & & \\
Type of PAS & \\
Non-cesarean & 0.33 & $0.88-1.21$ \\
Number of PAS ${ }^{\dagger}$ & & \\
At least 2 PAS & 4.96 & $1.27-19.40$ \\
SSA & & \\
Yes & 2.79 & $1.16-6.71$ \\
Yeiomyomas from patient information & & \\
Yes & 2.39 & $0.86-6.68$ \\
Perioperative obvious leiomyomas $^{\ddagger}$ & & \\
Yes & 2.49 & $1.07-5.78$ \\
\hline
\end{tabular}

PAS: Previous abdominal surgery, SSA: Skin scar anomaly, OR: Odds ratio, $\mathrm{CI}$ : Confidence interval, * : computed for patients with a unique PAS ( $\mathrm{n}=$ $42),{ }^{\dagger}$ : computed only for patients with PAS, ${ }^{\ddagger}$ : patients who had no information on having leiomyomas or not $(n=22)$, were excluded from analysis.

Comparing patients who underwent a unique PAS, the "non-cesarean" group presented less adhesions than "cesarean" group, but the difference was not significant [OR: 0.33 , CI95 (0.088 - 1.21)].

When patients had SSA, they were 3 times more likely to have adhesions than other patients [OR: 2.79, CI95 (1.16 - 6.71)]. Patients who self-reported to have or to have had leiomyomas, had non-significantly 2 times more adhesions than other patients [OR: 2.39, CI95 (0.86 -
6.68)]. But, the difference between groups was statistically significant with obvious leiomyomas observed during surgery [OR: 2.49, CI95 (1.07 - 5.78)]. There were no difference in the distribution of PAS grouped as "CS" versus "non-CS" in patients with and without obvious leiomyomas during surgery $(\mathrm{p}=0.646)$ (Table 4).

In a logistic regression analysis, the history of PAS and the presence of obvious leiomyomas during surgery were the only factors which remained associated significantly to adhesions with $\mathrm{p}=0.000$ and $\mathrm{p}=0.037$ respectively (Table 5).

\section{DISCUSSION}

Based on laparotomy and laparoscopy which are the gold standard methods for the diagnosis [6], the overall frequency of adhesions in the present study was $41.74 \%$. When considering postoperative adhesions, our frequency of $65.08 \%$ turned close to $67 \%$ found by Weibel et al. [29], but lower than $93 \%$ by Menzies et al. [7]. In patients without PAS, we found $13.46 \%$ of adhesions, slightly higher than $10.4 \%$ reported by Menzies et al. [7] but lower than $28 \%$ by Weibel et al. [29] and $47 \%$ by Shokeir et al. [19]. The adhesions frequency of our series is close to $44.45 \%$ reported by Weibel et al. [29], working on 752 autopsies conducted in women and men, and to $43 \%$ found by Salim et al. [27], studying adhesions in relation to abdominal scar in repeat cesarean delivery.

Table 4. Patients with history of PAS grouped following the evidence of leiomyomas.

\begin{tabular}{ccccc}
\hline & \multicolumn{2}{l}{ Leiomyomas during surgery } & Total & $\mathbf{p}$ \\
\hline PAS & Yes & No & & \\
CS & 8 & 18 & 26 & 0.646 \\
Non-CS & 7 & 20 & 27 & \\
Combined & 4 & 6 & 10 & \\
Total & $\mathbf{1 9}$ & $\mathbf{4 4}$ & $\mathbf{6 3}$ & \\
\hline
\end{tabular}

CS: Cesarean section.

Table 5. Determinants of adhesions.

\begin{tabular}{ccccc}
\hline Variable & OR & Standard Error & Wald & $\mathbf{p}$ \\
\hline $\begin{array}{c}\text { History of PAS } \\
\text { Yes }\end{array}$ & 11.79 & 0.51 & 23.48 & 0.000 \\
Obvious leiomyomas & & & & \\
Yes & 2.89 & 0.51 & 4.34 & 0.037 \\
SSA & & & & \\
Yes & 2.29 & 0.51 & 2.68 & 0.102 \\
\hline
\end{tabular}

PAS: Previous abdominal surgery, SSA: Skin scar anomaly, OR: Odds Ratio. 
But it is somewhat higher than that of $35.5 \%$ found by Brill et al. [20] in women undergoing laparoscopy. Our postoperative frequency of adhesions falls in the range of $63 \%-97 \%$ mostly reported in the literature $[4,7]$. The frequency of adhesions can vary according to many factors such as the type and the number of PAS, the type of incision, etc. In the present study the most frequent PAS were $\mathrm{CD}$ and appendectomy which are reported to result in fewer adhesions [30].

Previous abdominal surgery is thus considered the major risk factor, which raises need for cautious selection of patients, particular technique of avoidance of organs injuries and potential use of costly anti-adhesions barriers. Characteristics of adhesions from their incidence to their complications are much diversified involving several factors such as individual factors [13-15] and environmental factors [16-18]. A certain frequency of adhesions in patients without PAS implies the contribution of other factors than abdominal surgery. Among those factors, the high prevalence of sexually transmitted infections together with the implication of endometriosis should be addressed in our area. In fact, Shokeir et al. [19] reported this high prevalence in patients with endometriosis and inflammatory disorders, but in the present study these conditions have not been analyzed.

As characteristics of patients, the two groups with and without adhesions were identical in terms of age, parity, level of education, economic level and the type of PAS; cesarean or not. This means that these factors have influenced neither the frequency of adhesions in each group nor the risk factors analyzed in the present study.

There were no severe adhesions in patients according to the ASG grading. This reflects the predominance of CD and appendectomy as PAS in the present study. Indeed, it has been reported that adhesion development is less following $\mathrm{CD}$ and appendectomy compared to other procedures [29,31,32]. In their literature review, Awonuga et al. [30] highlight the proposed five hypotheses that can explain why CD results in fewer adhesions: less tissue hypoxia, less movement in the lower uterine segment, location of the incision on the lower segment covered by the bladder which is constantly being filled and emptied disrupting any fibrinous strands, less number of incisions, and rare hematoma within the low transverse incision.

The uterus and the bladder were the most associated organs to adhesions in the present study. These findings are different from those of many authors who reported these adhesions more likely to be associated with the omentum $[7,20,27]$. The difference noticed can be understood by the fact that, in our study, CD had been predominantly practiced as PAS than other procedures. Accordingly, this procedure leads mostly to pelvic adhesions involving organs in the anterior cul-de-sac [30].
There are several risk factors reported as related to adhesion formation [21] including age, height and weight that are subjects to divergent results $[17,29]$. The history of a PAS is the most studied factor in adhesion formation. As expected, we found that patients with PAS, irrespective of the type or the number of those PAS, were 12 times likely to have adhesions than patients without PAS. This is in agreement with many studies which reported a strong association between PAS and adhesion development $[7,29,33,34]$. But these findings differ from those reported by Shokeir et al. [19] working on infertile women who underwent laparoscopy for various procedures. Those authors did not notice any increased risk when they compared patients with and without PAS. The disparity can be explained by the fact that they worked on a selected group namely infertile women. In fact, many other factors apart from PAS, such as inflammatory diseases and endometriosis are mostly found to be involved in the occurrence of infertility.

As part of the surgical factor, adhesions were found 5 times more likely in patients with at least two PAS than in those with a unique PAS. Brill et al. [20], working on women undergoing laparoscopy and who had prior laparotomies, did not find difference between the two similar groups, as Salim et al. [27] did not, in their study on abdominal scar and adhesions in women undergoing cesarean delivery. However, our results are in accordance with that found by Luijendijk et al. [35] and with the established risk factors of adhesions reported in the literature $[17,21,29]$, including the number of previous surgeries.

The similarity of the molecular environment between peritoneal adhesions, skin scar and leiomyomas has been studied in the literature [26] although conclusions are not definitive. In bivariate analyses, we found that a SSA and a perioperative establishment of leiomyomas were both statistically associated with adhesions apart from the history and the number of a PAS. But when integrated in a logistic model, only leiomyomas and a history of PAS persisted as determinants of adhesions risk. We also found that PAS were distributed equally in the groups with and without leiomyomas $(\mathrm{p}=0.646)$. Accordingly, we cannot speculate that leiomyomas could have contributed to the need for operative delivery or to the myomectomy which could have caused more adhesions in this group. Some questions arise then about the accurate association between those three conditions which have to be investigated in further clinical researches. Salim et al. [27] studying the relation between surgical skin scar of a previous CD and peritoneal adhesions, established a correlation between a depressed abdominal scar and the severity of peritoneal adhesions. The results reported by Luo et al. [26] indicated that the molecular environment of leiomyomas may be more comparable to peritoneal 
adhesions than to keloids and incisional scars at least at the late stage of their wound healing. In addition, excess production and deposition of extracellular matrix in leiomyomas, keloids, skin scars and peritoneal adhesions has been demonstrated in many previous studies [26,36, 37]. Moreover, altered production of several proinflammatory and profibrotic cytokines has been reported in pathogenesis of these conditions and other fibrotic disorders $[38,39]$.

This study is limited by the design and the relatively small size of the sample. Given those facts, subgroups could not be constituted adequately. Again, characteristics of patients according to the history of pelvic inflammatory disease or endometriosis and the perioperative diagnosis were not considered in the present study, which could allow analyses of other coexisting risk factors of adhesions.

In the other hand, we clinically showed the possible association between peritoneal adhesions, SSA and leiomyomas. Therefore, well designed studies have to be conducted to reinforce these results and to investigate the accurate clinical relation between those three conditions, in order to offer new assets in recognizing patients at high risk.

\section{CONCLUSION}

Abdominal and pelvic adhesions represent a frequent condition in our surgical practice. Although the history of previous laparotomy is the most important risk factor, there is a non-negligible amount of adhesions due to other risk factors. Leiomyomas and skin scar anomaly are other factors that may be considered to allow a cautious selection of high risk patients who must benefit from particular attention. This is to act on the prevention of adhesions occurrence and/or the avoidance of adhesions-related injuries during surgery.

\section{ACKNOWLEDGEMENTS}

The authors are deeply grateful to Professors Tandu- Umba, Tozin and Lokomba, all from the Department of Obstetrics and Gynecology, for their scientific advice to the study.

\section{REFERENCES}

[1] Coccolini, F., Ansaloni, L., Manfredi, R., Campanati, L., Poiasina, E., Bertoli, P., Capponi, M.G., et al. (2013) Peritoneal adhesion index (PAI): Proposal of a score for the “ignored iceberg” of medicine and surgery. World Journal of Emergency Surgery, 8, 6.

http://dx.doi.org/10.1186/1749-7922-8-6

[2] DeWilde, R.L. and Trew, G. (2007) Postoperative abominal adhesions and their prevention in gynaecological surgery. Expert consensus position. Expert Consensus Position Gynecological Surgery, 4, 243-253. http://dx.doi.org/10.1007/s10397-007-0333-2

[3] Oboh, A. and Trehan, A.K. (2007) Pelvic adhesion formation at second-look surgery after laparoscopic partial and total peritoneal excision for women with endometriosis. Gynecological Surgery, 4, 261-265. http://dx.doi.org/10.1007/s10397-007-0299-0

[4] Arung, W., Meurisse, M. and Detry, O. (2011) Pathophysiology and prevention of postoperative peritoneal adhesions. World Journal of Gastroenterology, 17, 4545-4553. http://dx.doi.org/10.3748/wjg.v17.i41.4545

[5] Diamond, M.P. and Freeman, M.L. (2001) Clinical implications of postsurgical adhesions. Human Reproduction, 7, 567-576. http://dx.doi.org/10.1093/humupd/7.6.567

[6] Nzau, N.E., Mbuyi-Muamba, J.M., Mboloko, E. and Lebwaze, M.B. (2012) Physiopathologie et anatomopathologie des adhérences péritonéales et pelviennes. Une revue de la littérature. Annals of African Medicine, 6, 12941306.

[7] Menzies, D. and Ellis, H. (1990) Intestinal obstruction from adhesions-How big is the problem? Annals of The Royal College of Surgeons of England, 72, 60-63.

[8] Chen, M.J., Chen, T.Y., Chen, Y.M. and Hsu, Y.C. (2012) The effects of postoperative hyperbaric oxygen treatment on intra-abdominal adhesions in rats. International Journal of Molecular Sciences, 13, 12224-12231. http://dx.doi.org/10.3390/ijms131012224

[9] Miller, G., Boman, J., Shrier, I. and Gordon, P.H. (2000) Etiology of small bowel obstruction. The American Journal of Surgery, 180, 33-36. http://dx.doi.org/10.1016/S0002-9610(00)00407-4

[10] Gonzalez-Quintero, V.H. and Cruz-Pachano, F.E. (2009) Preventing adhesions in Obstetric and Gynecologic surgical procedures. Reviews in Obstetrics and Gynecology, 2, 38-45.

[11] Sikirica, V., Bapat, B., Candrilli, S.D., Davis, K.L., Wilson, M. and Johns, A. (2011) The inpatient burden of abdominal and gynecological adhesiolysis in the US. BMC Surgery, 1, 13. http://dx.doi.org/10.1186/1471-2482-11-13

[12] Kavic, S.M. (2002) Adhesions and adhesiolysis: The role of laparoscopy. JSLS, 6, 99-109.

[13] Brüggmann, D., Tchartchian, G., Wallwiener, M., Münstedt, K., Tinneberg, H.R. and Hackethal, A. (2010) Intraabdominal Adhesions: Definition, origin, significance in surgical practice, and treatment options. Deutsches Ärzteblatt International, 107, 769-775.

[14] Attard, J.A.P. and MacLean, A.R. (2007) Adhesive small bowel obstruction: Epidemiology, biology and prevention. Canadian Journal of Surgery, 50, 291-300.

[15] Torre, M., Favre, A., Patro, P., Brizzolara, A. and Martucciello, G. (2002) Histologic study of peritoneal adhesions in children and in a rat model. Pediatric Surgery International, 18, 673-676.

[16] Erdogan, E., Celayir, S., Eroglu, E. and Yilmaz, E. (2000) The relation between human leukocyte antigen (HLA) distribution and intestinal obstruction and adhesions in childhood: Preliminary report. Pediatric Surgery International, 16, 374-376.

http://dx.doi.org/10.1007/s003830000350 
[17] Schnüriger, B., Barmparas, G., Branco, B.C., Lustenberger, T., Inaba, K. and Demetriades, D. (2011) Prevention of postoperative peritoneal adhesions: A review of the literature. The American Journal of Surgery, 201, 111-121. http://dx.doi.org/10.1016/j.amjsurg.2010.02.008

[18] Hammoud, A., Gago, L.A. and Diamond, M.P. (2004) Adhesions in patients with chronic pelvic pain: A role for adhesiolysis. Fertility and Sterility, 82, 1483-1491. http://dx.doi.org/10.1016/j.fertnstert.2004.07.948

[19] Shokeir, T., Badawy, A. and Abo-Hashem, H. (2008) Preoperative risk factors for intraabdominal adhesions should not contraindicate surgical laparoscopy for infertility. JSLS, 12, 267-272.

[20] Brill, A.I., Nezhat, F., Nezhat, C.H. and Nezhat, C. (1995) The incidence of adhesions after prior laparotomy: A laparoscopic appraisal. Obstetrics \& Gynecology, 85, 269272. http://dx.doi.org/10.1016/0029-7844(94)00352-E

[21] Nzau, N.E., Mboloko, E., Mbuyi-Muamba, J.M. and Lebwaze, M.B. (2012) Epidémiologie, conséquences et traitement des adhérences péritonéales et pelviennes. Une revue de la littérature. Annals of African Medicine, 5, 11871200.

[22] Hirschelmann, A., Tchartchian, G., Wallwierner, M., Hackethal, A. and DeWilde R.L. (2012) A review of the problematic adhesion prophylaxis in gynaecologic surgery. Archives of Gynecology and Obstetrics, 285, 10891097. http://dx.doi.org/10.1007/s00404-011-2097-1

[23] Allegranzi, B., Nejad, S.B., Combescure, C., Graafmans, W., Attar, H. and Donaldson, L., et al. (2011) Burden of endemic health-care-associated infection in developing countries: Systematic review and meta-analysis. Lancet, 377, 228-241. http://dx.doi.org/10.1016/S0140-6736(10)61458-4

[24] World Health Organisation (2008) Safe surgery saves lives: The second global patient safety challenge. http://whlibdoc.who.int/hq/2008/WHO_IER_PSP_2008.0 7_eng.pdf

[25] Da Ros, C.T. and Schmitt, C.D.S. (2008) Global epidemiology of sexually transmitted diseases. Asian Journal of Andrology, 10, 110-114. http://dx.doi.org/10.1111/j.1745-7262.2008.00367.x

[26] Luo, X., Pan, Q., Liu, L. and Chegini, N. (2007) Genomic and Proteomic profiling II: Comparative assessment of gene expression profiles in leiomyomas, keloids, and surgically-induced scars. Reproductive Biology and Endocrinology, 5, 35.

http://dx.doi.org/10.1186/1477-7827-5-35

[27] Salim, R., Kadan, Y., Nachum, Z., Edelstein, S. and Shalev, E. (2008) Abdominal scar characteristics as a predictor of intra-abdominal adhesions at repeat cesarean delivery. Fertility and Sterility, 90, 2324-2327. http://dx.doi.org/10.1016/j.fertnstert.2007.10.037

[28] Mage, G., Wattiez, A., Canis, M., Pouly, J.L., Alexander, F. and Bruhat, M. (2000) Classification of adhesions. In: G. S. diZerega, Ed., Peritoneal Surgery, Springer, New
York, 221-228.

[29] Weibel, M.A., Majno, G. and Jagelman, D.G. (1973) Peritoneal adhesions and their relation to abdominal surgery: A postortem study. The American Journal of Surgery, 126, 345-353. http://dx.doi.org/10.1016/S0002-9610(73)80123-0

[30] Awonuga, A.O., Fletcher, N.M., Saed, G.M. and Diamond, M.P. (2011) Postoperative adhesion development following cesarean and open intra-abdominal gynecologic operations: A review. Reproductive Sciences, 18, 11661185. http://dx.doi.org/10.1177/1933719111414206

[31] Morales, K.J., Gordon, M.C. and Bates Jr., G.W. (2007) Postcesarean delivery adhesions associated with delayed delivery of infant. American Journal of Obstetrics \& Gynecology, 196, e461-e466. http://dx.doi.org/10.1016/j.ajog.2006.12.017

[32] Tulandi, T., Agdi, M., Zarei, A., Miner, L. and Sikirica, V. (2009) Adhesion development and morbidity after repeat cesarean delivery. American Journal of Obstetrics \& Gynecology, 201, e51-e56. http://dx.doi.org/10.1016/j.ajog.2009.04.039

[33] Ellis, H., Moran, B.J., Thompson, J.N., Parker, M.C., Wilson, M.S., Menzies, D. et al. (1999) Adhesion-related hospital readmissions after abdominal and pelvic surgery: A retrospective cohort study. Lancet, 353, 1476-1480. http://dx.doi.org/10.1016/S0140-6736(98)09337-4

[34] Kamel, R.M. (2010) Prevention of postoperative peritoneal adhesions. European Journal of Obstetrics \& Gynecology and Reproductive, 150, 111-118. http://dx.doi.org/10.1016/j.ejogrb.2010.02.003

[35] Luijendijk, R.W., de Lange, D.C.D., Wauters, C.C.A.P., Duron, J.J., Pailler, J.L., Camprodon, B.R. et al. (1996) Foreign material in postoperative adhesions. Annals of Surgery, 223, 242-248. http://dx.doi.org/10.1097/00000658-199603000-00003

[36] Catherino, W.H., Leppert, P.C., Stenmark, M.H., Payson, M., Podog-Nahari, C., Nieman, L.K. and Segars, J.H. (2004) Reduced dermatopontin expression is a molecular link between uterine leiomyomas and keloids. Genes Chromosomes Cancer, 40, 204-217. http://dx.doi.org/10.1002/gcc.20035

[37] Midwood, K.S., Williams, L.V. and Schwarzbauer, J.E. (2004) Tissue repair and the dynamics of the extracellular matrix. The International Journal of Biochemistry \& Cell Biology, 36, 1031-1037. http://dx.doi.org/10.1016/j.biocel.2003.12.003

[38] Martin, P. and Leibovich, S.J. (2005) Inflammatory cells during wound repair: The good, the bad and the ugly. Trends in Cell Biology, 15, 599-607. http://dx.doi.org/10.1016/j.tcb.2005.09.002

[39] Romagnani, P., Lasagni, L., Annunziato, F., Serio, M. and Romagnani, S. (2004) CXC chemokines: The regulatory link between inflammation and angiogenesis. Trends in Immunology, 25, 201-209. http://dx.doi.org/10.1016/j.it.2004.02.006 